\title{
INTERAKSI BAHASA CERAMAH GUS MUWAFIQ DALAM ACARA MAULID NABI DI ISTANA PRESIDEN BOGOR
}

\author{
Muhammad Bahruddin \\ Universitas Negeri Surabaya \\ Jl. Ketintang,Kec Gayungan, Kota Surabaya, Indonesia \\ Pos-el : muh.bahruudin01@gmail.com
}

\begin{abstract}
This research examines the interaction of language Gus Muwafiq talk in the event of a maul prophet at the presidential palace bogor but only focuses on language variations and interfering in a code adopted by Gus Muwafiq talk. The kind of research used descriptive qualitative. In this research will be elaborate about the kind of research variation language used on Gus Muwafiq talk. The research results (1) variation language used in a Gus Muwafiq in the event of a maul prophet at the palace bogor divided into four variety of, which is its diversity of official, business, relax and familiar. That fourth of its diversity of relax and familiar used most often. The diversity of is very suitable when talks due to a lector will try to catch up with the audience or an audience through a language that contains sense of humor. So that his hearers or an audience share my enthusiasm to lectures ever listens. (2) intervening code that is added to talk Gus Muwafiq in the event of a maul prophet in the palace bogor found the form of intervening code in talk gus muwafiq in the form of said, phrase, and clause.
\end{abstract}

Keywords: variation language, intervening code

\begin{abstract}
Abstrak
Penelitian ini meneliti interaksi bahasa ceramah Gus Muwafiq dalam acara maulid Nabi di istana Presiden Bogor tetapi hanya menfokuskan pada variasi bahasa dan campur kode yang digunakan pada ceramah oleh Gus Muwafiq. Jenis penelitian yang digunakan deskriptif kualitatif. Pada penelitian ini akan diuraikan mengenai jenis penelitian variasi bahasa yang digunakan pada ceramah Gus Muwafiq. Hasil penelitian (1) Variasi bahasa yang digunakan pada ceramah Gus Muwafiq dalam acara maulid Nabi di istana Bogor terbagi menjadi empat ragam, yaitu ragam resmi, usaha, santai dan akrab. Dari keempat tersebut ragam santai dan akrablah yang digunakan paling banyak. Ragam tersebut sangat cocok digunakan saat ceramah dikarenakan penceramah akan berusaha untuk mengakrabkan dengan pendengar atau audiens lewat bahasa yang mengandung humor. Sehingga pendengar atau audiens memiliki ketertarikan terhadap ceramah yang didengarkan. (2) Campur kode yang terdapat pada ceramah Gus Muwafiq dalam acara maulid Nabi di istana Bogor ditemukan
\end{abstract}


bentuk campur kode pada ceramah Gus Muwafiq yaitu berupa kata, frasa, serta klausa.

Kata Kunci : variasi bahasa, campur kode

\section{PENDAHULUAN}

Manusia pada hakikatnya adalah makhluk individu dan makhluk sosial, kehidupannya akan selalu ditandai dengan adanya interaksi ataupun komunikasi, baik interaksi dengan alam, interaksi dengan sesama maupun interaksi dengan Tuhannya. Interaksi secara verbal diartikan sebagai hubungan antara orang yang satu dan yang lain dengan menggunakan bahasa. Sementara itu, bahasa menurut Kridalaksana (2008: 21) merupakan suatu sistem lambang bunyi yang arbitrer yang digunakan oleh para anggota kelompok sosial untuk bekerja sama, berkomunikasi, dan mengidentifikasi diri.

Manusia adalah makhluk berbahasa (homolingual). Di dalam kehidupan bermasyarakat, hampir dalam semua kegiatan manusia menggunakan bahasa. Bahasa memegang peranan penting dalam kehidupan bermasyarakat yakni sebagai sarana komunikasi. Tanpa bahasa dapat dipastikan bahwa segala macam kegiatan berinteraksi dalam masyarakat akan lumpuh. Mengingat pentingnya bahasa dalam menjalankan segala aktivitas seharihari, tentu setiap anggota masyarakat selalu terlibat dalam komunikasi, baik bertindak sebagai komunikator (pembicara) maupun sebagai komunikan (penyimak). Peristiwa-peristiwa komunikasi yang berlangsung tersebut dapat dijadikan tempat atau media untuk mengungkapkan ide, gagasan, isi pikiran, maksud, realitas, dan sebagainya. Bahasa adalah sistem lambang bunyi yang arbitrer yang dipergunakan oleh para angggota kelompok sosial untuk bekerja sama, berkomunikasi, dan mengidentifikasi diri.

Kedwibahasaan merupakan masalah yang sederhana terkait dengan perihal penguasaan (individu atau kelompok) terhadap lebih dari satu bahasa (dua bahasa). Kedwibahasaan adalah pengetahuan tentang dua bahasa. Kedwibahasaan juga berkaitan dengan berbagai disiplin ilmu seperti psikologi, neurologi, sosiologi, dan antropologi. Salah satu efek dari kedwibahasaan yang lazim dibicarakan adalah alih kode dan campur kode. Istilah alih kode (code switching) dan campur kode (code mixing), merupakan istilah yang sama-sama menggunakan dua bahasa dalam satu peristiwa tindak tutur. Menurut Giyoto (2013) alih 
kode adalah peristiwa peralihan dari kode yang satu ke kode yang lain. Alih kode adalah suatu peristiwa mengalihkan atau mengubah kode yang dilakukan secara sengaja oleh seseorang komunikan atau penutur sesuai dengan hasil penilaiannya terhadap konteks komunikasi untuk menimbulkan efek tertentu. Kecenderungan beralih kode disebabkan oleh (1) kecakapan berbahasa, (2) keterikatan berbahasa, dan (3) interferensi kedwibahasaan. Sementara itu, Rahadi (2010) menyatakan bahwa campur kode adalah penggunaan dua bahasa atau ragam bahasa dalam suatu tindakan berbahasa.

Salah satu sarana yang digunakan menyampaikan pesan kepada orang lain adalah melalui ceramah atau pidato. Ceramah adalah pidato di hadapan banyak pendengar, mengenai suatu hal atau pengetahuan. Melalui ceramah ataupun pidato seseorang dapat menyampaikan gagasan, pikiran atau informasi kepada orang banyak secara lisan. Dalam pelaksanaanya antara pidato dan ceramah tidak dapat dibedakan, keduanya sama-sama menyampaikan suatu gagasan atau pesan kepada khalayak. Hanya saja yang membedakan keduanya adalah situasi, tempat, waktu (kesempatan), tema dan sumbernya. Ceramah lebih bersifat khusus untuk masalah keagamaan. Dalam ceramah tentu setiap penceramah mempunyai variasi bahasa yang digunakan agar menarik pendengar atau audiens. Selain variasi bahasa, penceramah akan sering menggunakan campur kode agar pendengar lebih memahami apa yang disampaikan.

Dalam ceramah $\begin{array}{r}\text { biasanya } \\ \text { seringkali }\end{array}$
penceramah
menggunakan variasi bahasa, alih kode dan campur kode untuk menarik perhatian pendengar. Salah satunya penceramah KH. Ahmad Muwafiq yang lebih dikenal dengan Kyai Muwafiq atau Gus Muwafiq adalah salah satu ulama yang berasal dari Yogyakarta. Gus Muwafiq dikenal sebagai salah satu ulama' yang tidak hanya faham ilmu agama, tetapi beliau juga mendalami berbagai ilmu lain, salah satunya ilmu sejarah dan peradaban yang disampaikan dengan bahasa yang lugas dan mudah diterima.

Dari penjelasan tersebut, peneliti tertarik meneliti interaksi bahasa ceramah Gus Muwafiq dalam acara maulid Nabi di istana Presiden Bogor tetapi hanya menfokuskan pada variasi bahasa dan campur kode yang digunakan pada ceramah oleh Gus Muwafiq. Fokus Permasalahan Bagaimana bentuk variasi bahasa yang digunakan pada ceramah gus muwafiq dalam acara maulid Nabi di istana presiden Bogor?

Bagaimana campur kode digunakan pada ceramah Gus Muwafiq dalam 
acara maulid Nabi di istana presiden Bogor?

Konsep teori yang digunakan untuk melandasi penelitian ini secara garis besar meliputi teori variasi bahasa dan alih kode.

\section{Variasi Bahasa}

Masyarakat pengguna bahasa bukanlah kumpulan manusia yang homogen, sehingga wujud bahasa menjadi bervariasi. Variasi bahasa disebabkan oleh adanya kegiatan interaksi sosial yang dilakukan oleh masyarakat atau kelompok yang sangat beragam. Holmes (2017: 6) menyebutkan "within each of linguistic levels there is variation which offers the speaker a choice of ways of expression". Pernyataan tersebut menjelaskan bahwa dalam masingmasing tingkat linguistik ini ada variasi yang menawarkan pembicara pilihan cara berekspresi.

Lebih lanjut disebutkan "variety is a sociolinguistic term referring to language in context. A variety is a set of linguistic form used under specific social circumstances, i.e. with a distinctive social distribution. Variety is therefore a broad term which includes different accents, different linguistic styles, different dialects and even different languages which contrast with each other for social reason. It has proved a very useful sociolinguistic term because it is linguistically neutral and covers all the different realizations of the abstract concept "language" in different social contexts" (Holmes, 2017: 9).
Kutipan tersebut menyatakan bahwa variasi adalah istilah sosiolinguistik yang mengacu pada bahasa dalam konteks. Variasi adalah serangkaian bentuk linguistik yang digunakan dalam keadaan-keadaan sosial tertentu, yaitu dengan distribusi sosial yang khas. Oleh karena itu, variasi merupakan istilah luas yang mencakup aksen yang berbeda, gaya bahasa yang berbeda, dialek yang berbeda dan bahkan bahasa yang berbeda kontras satu sama lain untuk alasan sosial. Hal ini merupakan istilah sosiolinguistik yang terbukti berguna karena mencakup semua perbedaan yang nyata dari konsep abstrak 'bahasa' dalam konteks sosial yang berbeda. Pernyataan di atas sejalan dengan yang dikemukakan oleh Giyoto (2013) bahwa variasi bahasa adalah sejenis ragam bahasa yang pemakaiannya disesuaikan dengan fungsi dan situasinya tanpa mengabaikan kaidah-kaidah pokok yang berlaku dalam bahasa yang bersangkutan. Sejalan dengan hal itu, Rahadi (2010) mengemukakan setiap bahasa mempunyai banyak ragam yang dipakai dalam keadaan dan tujuan yang berbeda-beda.

Variasi bahasa berbeda-beda disesuaikan dengan faktor dominan yang menentukan adanya variasi bahasa. Variasi bahasa yang berkaitan dengan tempat terjadinya penggunaan bahasa atau letak geografis penggunaan bahasa 
disebut variasi geografis, sedangkan variasi bahasa yang berhubungan dengan kelompok sosial yang menggunakan bahasa disebut variasi sosial. Variasi bahasa yang berhubungan dengan penggunaannya, situasi berbahasa dan/atau tingkat formalitas variasi fungsional. Variasi bahasa yang berhubungan dengan kode bahasa disebut variasi kode.

Variasi bahasa disebabkan oleh adanya status sosial dan fungsi bahasa yang bermacam-macam sebagai alat interaksi sosial dalam masyarakat. Terjadinya variasi bahasa itu bukan hanya disebabkan oleh penuturnya yang heterogen, tapi juga karena kegiatan interaksi sosial yang mereka lakukan sangat beragam. Jadi, setiap kegiatan memerlukan dan menyebabkan terjadinya keragaman bahasa (Chaer, 2010: 6).

Dalam hal variasi atau ragam bahasa ini ada dua pandangan. Pertama variasi atau ragam bahasa itu dilihat sebagai akibat adanya keragaman sosial penutur bahasa itu dan keragaman fungsi bahasa itu. Kedua, variasi atau ragam bahasa itu sudah ada untuk memenuhi fungsinya sebagai alat interaksi dalam kegiatan masyarakat yang beraneka ragam (Chaer dan Agustina, 2010: 62).

Berkaitan dengan fungsi bahasa dalam ceramah maka jenis variasi bahasa mengarah pada variasi dari segi penggunaannya atau variasi fungsional. Soeparno (2009: 57) mengemukakan bahwa variasi fungsional ini dapat disebut dengan istilah fungsiolek. Sementara itu Chaer dan Agustina (2010: 68) menyebutkan bahwa variasi bahasa berkenaan dengan penggunaannya, pemakaiannya atau fungsinya disebut fungsiolek (Rahadi, 2010), ragam atau register.

$$
\text { Variasi ini biasanya }
$$

dibicarakan berdasarkan bidang penggunaan, gaya atau tingkat keformalan dan sarana penggunaan. Variasi bahasa berdasarkan berdasarkan bidang penggunaannya ini adalah menyangkut bahasa itu digunakan untuk apa. Misalnya, bidang sastra, jurnalistik, militer, pertanian, pelayaran, perdagangan, pendidikan dan kegiatan keilmuan (Chaer dan Agustina, 2010: 68). Variasi bahasa berdasarkan tingkat keformalannya adalah menyangkut bahasa itu digunakan dalam situasi seperti apa: khidmat, resmi, biasa, santai dan akrab atau intim (Chaer dan Agustina, 2010: 72).

Berdasarkan tingkat keformalannya, Martin Joos (dalam Chaer dan Agustina, 2010:70) membagi variasi bahasa menjadi lima macam yaitu ragam beku (frozen), ragam remi (formal), ragam usaha (konsultatif), ragam santai (casual), dan ragam akrab (intimate). 


\section{Campur Kode}

Pemakaian bahasa dalam konteks bilingualisme selain ada kecenderungan terjadinya alih kode juga menyebabkan banyaknya proses campur kode (code mixing). Keduanya merupakan gambaran adanya saling ketergantungan antar bahasa, akan tetapi alih kode lebih menekankan pada fungsi konteks dan relevansi situasi sebagai ciri kebergantungannya. Campur kode sendiri dapat diartikan sebagai proses pemakaian dua bahasa atau lebih dengan saling memasukkan unsur-unsur bahasa yang satu ke dalam bahasa yang lain dalam satu klausa yang sama. Alasan seseorang mencampurkan beberapa unsur kode bahasa yang berbeda (campur kode) dalam suatu tindak berbahasa adalah ingin menciptakan adanya situasi yang santai sehingga pertuturan berlangsung tanpa beban. Oleh karena itu, selain dukungan suasana yang cenderung santai, tanpa beban, campur kode biasanya juga terjadi dalam situasi informal. Selain itu tidak jarang campur kode merupakan cerminan sifat pamer (sombong) bagi penuturnya untuk menunjukkan kemahiran berbahasa asing tertentu, misalnya bahasa Inggris, Belanda, dan lain sebagainya yang sering kita dengar dalam suatu ceramah dan percakapan antar ibu rumah tangga dalam kegiatan arisan PKK. Hal yang catatan utama bahwa dalam peristiwa campur kode ini pemakaian unsur bahasa lain hanya sebatas leksikon (kata atau frase), belum melampaui batas unit bahasa yang lebih besar seperti sintaksis.

Ditinjau dari aspek nilai sumbangan (kontribusi) campur kode dibedakan menjadi 2 (dua) jenis yaitu campur kode positif, dan campur kode negatif.

Campur kode positif dimaksudkan sebagai bentuk pemakaian unsur bahasa lain seperti apa adanya. Penutur mengambil dan memakai unsur bahasa atau ragam lain secara tetap tanpa mengubahnya sebab tidak ada pedanan yang tepat pada bahasa yang dipakainya. Keadaan ini banyak dilakukan penutur saat bebicara melampaui batas wilayah bahasa yang bersangkutan, sehingga unsur leksikon yang tersedia kurang mendukungnya. Pengambilan unsur bahasa atau ragam lain yang sifatnya lebih memperkaya khasanah pengembangan suatu bahasa semacam ini bernilai positif dan bersifat integratif (menguntungkan). Hal demikian biasanya terkait dengan bidang keilmuan baru dan berbeda. Sedangkan campur kode negatif adalah bentuk pengambilan dan pemakaian unsur bahasa lain, sementara dalam bahasa yang bersangkutan terdapat unsur kata yang sepadan, produktif dan representatif. Keadaan yang demikian dipandang negatif, kurang baik bagi pembinaan dan 
$\begin{array}{lrr}\text { pengembangan } & \text { bahasa } & \text { yang } \\ \text { bersangkutan. } & \text { Peristiwa } & \text { campur } \\ \text { kode yang demikian } & \text { bersifat } \\ \text { interferensif, } & \text { yaitu } \\ \text { percampuradukan antar unsur } & \text { unsur }\end{array}$

bahasa yang bersifat merugikan.

Peristiwa interferensi demikian sering kita dengar dalam percakapan di lingkungan masyarakat kelas bawah dan bahkan anggota masyarakat yang cukup terpelajar.

Peristiwa campur kode disebabkan oleh beberapa alasan, yaitu (1) adanya keterbatasan padanan kata, (2) pengaruh pihak kedua, (3) kurang menguasai kode bahasa yang dipakai, dan (4) pengaruh unsur prestise.

Dalam penelitian ini, akan dibahas tentang bentukbentuk dari peristiwa campur kode. Adapun bentuk campur kode tersebut adalah berupa kata dasar, frase, serta klausa yang kesemuannya merupakan unsur yang terdapat dalam analisis sintaksis, yaitu analisis tentang hubungan antara tanda-tanda linguistik dengan halhal yang ditandainya atau analisis tentang makna atau arti dalam bahasa.

Kata dasar adalah kata yang belum mendapat tambahan yang berupa imbuhan (afiks) yang termasuk jenis morfem bebas. Dalam bahasa Indonesia kita memiliki empat kategori sintaksis utama: (1) verba atau kata kerja, (2) nomina atau kata benda, (3) adjektiva atau kata sifat, (4) adverbia atau kata keterangan. Frasa adalah kelompok kata yang merupakan bagian fungsional dari tuturan yang lebih panjang. Sedangkan frase adalah satuan sintaksis yang terdiri atas dua kata atau lebih yang tidak mengandung unsur predikasi. Selanjutnya terdapat bentuk klausa yang merupakan satuan sintaksis yang terdiri atas dua kata atau lebih, yang mengandung unsur predikasi. Istilah klausa dipakai untuk merujuk pada deretan kata yang paling tidak memiliki subjek dan predikat, tetapi belum memiliki intonasi atau tanda baca tertentu.

\section{METODE PENELITIAN}

Penelitian ini menggunakan jenis penelitian kualitatif. Menurut Arikunto (2013;21), data yang diperoleh dari penelitian kualitatif ialah data yang diujudkan dalam kata keadaan atau kata sifat. Moleong (dalam Arikunto 2013;22) juga berpendapat bahwa penelitian kualitatif adalah tampilan yang berupa kata-kata lisan atau tertulis yang dicermati oleh peneliti, dan benda-benda yang diamati sampai detailnya agar dapat ditangkap makna yang tersirat dalam dokumen atau bendanya. Menurut Sugiono $(2010 ; 1)$ metode penelitian kualitatif ini sering disebut metode penelitian naturalistik karena penelitiannya dilakukan pada kondisi yang alamiah (natural 
setting); disebut juga sebagai metode etnographi, karena pada awalnya metode ini lebih banyak digunakan untuk penelitian bidang antropologi budaya; disebut sebagai metode kualitatif, karena data yang terkumpul dan analisisnya lebih bersifat kualitatif.

Berdasarkan ciri-ciri penelitian kualitatif data yang digunakan dalam penelitian berupa kata-kata dan kalimat yang mengandung variasi bahasa dan campur kode yang digunakan pada ceramah Gus Muwafiq. Jenis penelitian ini adalah deskriptif. Artinya penelitian yang digunakan untuk mendeskripsikan suatu keadaan atau fenomena. Pada penelitian ini akan diuraikan mengenai jenis penelitian variasi bahasa yang digunakan pada ceramah Gus Muwafiq. Selain itu pengambilan data dilakukan secara alamiah. Proses penganalisisan data tidak melibatkan penghitungan secara statistik.

\section{HASIL DAN PEMBAHASAN}

Pada bagian ini akan
disajikan pembahasan hasil
penelitian mengenai variasi bahasa
dan campur kode pada ceramah
Gus Muwafiq dalam acara maulid
Nabi di istana Bogor.

1. Variasi bahasa

Variasi bahasa yang digunakan pada ceramah Gus Muwafiq dalam acara maulid Nabi di istana Bogor memiliki variasi bentuk bahasa, yaitu ragam resmi, usaha, santai dan akrab.

Bentuk variasi bahasa yang dominan digunakan pada ceramah Gus Muwafiq dalam acara maulid Nabi di istana Bogor, yaitu

a. Ragam Resmi

Ragam resmi digunakan untuk menciptakan suasana yang resmi pada ceramah, ragam tersebut digunakan oleh Gus Muwafiq pada awal pembukaan ceramah di istana presiden Bogor dikarenakan untuk menghormati tamu undangan.

Berikut adalah kutipan terkait dengan penggunaan ragam resmi pada ceramah Gus Muwafiq:

Bapak Presiden yang saya hormati, bapak wakil presiden, jajaran mentri kabinet kerja, yang saya hormati bapak mentri agama, bapak panglima, dan seluruh jajaran pemerintah Republik Indonesia, tamu undangan, para alim ulama' yang berbahagia. (VB/RS/AM/2018)

Pada kutipan tersebut merupakan contoh penggunaan ragam resmi oleh Gus Muwafiq dalam ceramah. Ucapan tersebut merupakan ucapan penghormatan untuk mengawali ceramah. Dengan menyapa para tamu undangan merupakan bentuk penghormatan.

b. Ragam Usaha

Ragam usaha merupakan ragam yang sering digunakan dalam ceramah agar tujuan dan isi ceramah dapat diterima oleh 
pendengar. Ragam usaha dapat dengan mudah dipahami dengan baik oleh pendengar.

Berikut adalah kutipan terkait dengan penggunaan ragam usaha pada ceramah Gus Muwafiq:

Ada yang menyebut ibrahim, ada yang menyebut abraham bahkan ada yang menyebut sebagai brahma. (VB/RU/AM/2018)

Umat islam mengenal ka'bah dengan batu dan tengahnya tidak ada isinya apa apa, kosong. Di India ada bangunan yang sama batu yang tidak ada isinya ditengah namanya stupa. Di islam ada namanya jabal rahmah sebuah tugu batu kemudian di india dikenal sebagai linngayoni. Ada air yang bernama zam zam ada air yang bernama ganggga yang mona, ada perjalanan suci dengan kain slempang disini ada berwarna putih, disina ada berwarna kuning. Setelah perjalanan suci, ada urusan yang sama terkait dengan rambut yang disini tahallul, disana digudul. Selesai perlanan suci semua itu ada darah yang disini ada qurban yang disana ada gadri dan kalau sudah bersujud meninggalkan hitam dua yang disana delapan. (VB/RU/AM/2018)

karena rasul adalah "khotamul anmbiya' wal mursalin" dan jejak kenabian yang mengarahkan kepada allah karena ada situs tertuanya dengan adanya ka'bah (VB/RU/AM/2018)
Bagaimana panglima perang kayak Sayyidina Umar bisa patuh sama orang yang tidak perna berkelahi, bagaimana Sayyidina Abu Bakar seorang konglomerat mau menuntun unta Rasulullah, bagaimana seorang gadis 10 tahun bergembira ria dinikah sama orang 50 tahun. (VB/RU/AM/2018)

bagaimana kita mengikuti Rasulullah ditempat yang jauh ini Rasulullah memberikan garis yang namanya Ahlusunnah wal Jamaah bahwa Rasulullah yang diajar pertama wal jamaahnya bernama sahabat waljamaahnya sabahat generasi keduan namanya tabi'in, tabi'in punya generasi berikutnya namanya tabi'it tabi'in dan kita ini adalah generasinya para ulama' yang cara pembelajarannya sangat berbeda. (VB/RU/AM/2018)

kalau kepalamu bocor seperti itu gak inget Allah inget apa udahlah habis sholat ditambal, maka habis sholat ada dzikir laa ilaa ha illallah (VB/RU/AM/2018)

Pada kutipan tersebut merupakan contoh penggunaan ragam usaha oleh Gus Muwafiq dalam ceramah. Pada kutipan (1) berisi tentang penyebutan nama Ibrahim yang ada beberapa nama yang berbeda, hal tersebut menjelaskan adanya keterkaitan hal yang ada di Islam dan agama lain. Pada kutipan (2) tersebut berisi 
tentang penjelasan sejarah tentang persamaan hal-hal yang ada di Islam Arab dan agama yang ada di India dengan menggunakan beberapa nama bangunan untuk membuktikan sejarah tersebut. Pada kutipan (3) tersebut berisi usaha menjelaskan bahwa Nabi Muhammad mempunyai jejak yang mengarah ke Allah yang dibuktikan dengan adanya situs tertuanya di Makkah. Pada kutipan menjelasakan hal hal yang membuat kita yakin bahwa Nabi memang pilihan Allah. Pada kutipan (5) menjelaskan bahwa cara pembelajaran dari generasi ke generasi selalu berbeda. Dan pada kutipan (6) menjelaskan alasan setelah sholat ada dzikir. Dapat disimpulkan bahwa ragam usaha, yaitu bahasa yang digunakan untuk memberikan penjelasan dengan memakai bahasa yang lain seperti istilah istilah.

\section{c. Ragam Santai}

Ragam santai dalam interaksi ceramah digunakan untuk menciptakan suasana yang santai antara penceramah dan pendengar. Hal ini disebabkan oleh waktu yang dilakukan ceramah lama sehingga untuk mengatasi kejenuhan maka penceramah menggunakan ragam santai. Sehingga pesan dari ceramah dapat tersampaikan.

Berikut adalah kutipan tuturan terkait dengan penggunaan ragam santai pada ceramah Gus Muwafiq: latihan dulu di alun alun bogor labaikallah humma ajaarr(VB/RS/AM/2018)

tidar tidur tok, solaman salaman bekalmu apa(VB/RS/AM/2018)

maka jangan memaksakan diri kurban pake unta nanti ditangkep oleh polisi karena nyuri untanya kebun raya bogor(VB/RS/AM/2018)

Pada kutipan tersebut merupakan contoh ragam santai yang digunakan oleh Gus Muwafiq pada ceramahnya. Dari data tersebut bisa dilihat penggunaan bahasa daerah yang membuat pendengar tetap santai mendengarkan ceramah.

d. Ragam Akrab

Ragam akrab merupakan ragam bahasa yang terdapat dalam variasi bahasa pada ceramah Gus Muwafiq. Ragam akrab ini digunakan untuk menciptakan suasana akrab dengan pendengar, mengadakan variasi dalam upaya memberikan perhatian kepada pendengar. Berikut adalah kutipan terkait dengan penggunaan ragam akrab dalam ceramah

Makanya kalau pak jokowi bisa menemukan tongkat itu tidak akan susah membangun jalan tol di indonesia (VB/RA/AM/2018) kalau orang jawa bilangnya mbah yaa pak presiden ya "kek, aku ini sebagai nabi terakhir(VB/RA/AM/2018) 
kalau dalam bahasanya bapak presiden

jabalkat.(VB/RA/AM/2018)

Sakitnya

tuh

disini.(VB/RA/AM/2018)

orang Indonesia terutama di kampungnya Bapak Presiden menyebut bulan Asyuro dengan bulan Syuro.(VB/RA/AM/2018)

lah sholat disini Allahu akbar karena sinyalnya jauh kita ini pemancar lokal biasa sinyalnya suka ilang(VB/RA/ AM/2018)

Kutipan-kutipan di atas menunjukkan penggunaan ragam akrab dengan kalimat yang mengandung humor untuk mengajak pendengar bercanda. Dengan humor pendengar akan merasa senang, tertarik, dan tidak bosan.

2. Campur kode

Peristiwa campur kode terjadi karena ketergantungan penutur terhadap pemakaian bahasa. Demikian pula yang terjadi dalam ceramah Gus Muwafiq. Beliau sering mencampurkan beberapa bahasa pada setiap ceramahnya, baik itu percampuran berupa bahasa Jawa maupun bahasa Arab ke dalam bahasa utama yakni bahasa Indonesia.

Berdasarkan data yang ditemukan, bentuk campur kode pada ceramah Gus Muwafiq yaitu berupa kata, frasa, serta klausa. Berikut ini akan dijelaskan bentukbentuk campur kode tersebut.

a. Campur kode berupa kata

Kata adalah satuan bahasa terkecil yang dapat berdiri sendiri. Berikut penulis akan menguraikan beberapa contoh bentuk campur kode yang menggunakan kata berupa nomina atau kata benda, verba atau kata kerja, dan adjektiva atau kata sifat dalam ceramah Gus Muwafiq. Berikut adalah kutipankutipan campur kode berupa kata:

2) matanya bisa melek kembali (CK/ AM/2018)

11) akhirnya mbalik ke belakang Rasul dipegang dipiting begini (CK/ AM/2018)

Endak ya Jibril (CK/AM/2018)

16) Saking senengnya orang ini lantas berjoget(CK/AM/2018)

20)Bagaimana panglima perang kayak Sayyidina Umar (CK/ AM/2018)

28) karena capek nunggu pegel sampe ada diuruki anjang anjang (CK/ AM/2018)

Dari kutipan tersebut, menunjukkan penggunaan campur kode berupa kata-kata dari bahasa Jawa seperti melek (terbuka), mbalik (kembali), endak (tidak), saking (sampai), kayak (seperti), pegel (capek) yang dicampur dengan bahasa Indonesia. 
b. Campur kode berupa frasa

Frasa adalah gabungan dua kata atau lebih yang bersifat nonpredikatif. Frasa adalah satuan sintaksis yang terdiri atas dua kata atau lebih yang tidak mengandung unsur prediksi. Adapun beberapa contoh campur kode berupa frasa dalam ceramah Gus Muwafiq akan diuraikan di bawah ini:

konsep yang ditawarkan adalah wa syaawirhum fil amri(CK/AM/2018) konsepnya disebut tafassahuu fiil majaliss (CK/AM/2018)

Dalilnya apa naumu shooimin ibadati (CK/AM/2018)

Dari kutipan tersebut dapat diketahui penggunaan campur kode berupa frasa dengan percampuran antara bahasa Indonesia dengan bahasa Arab.

c. Campur kode berupa klausa

Klausa merupakan satuan sintaksis yang terdiri atas dua kata atau lebih, yang mengandung unsur predikat, tetapi belum memiliki intonasi atau tanda baca tertentu. Dari peristiwa campur kode pada ceramah Gus Muwafiq ini, terdapat pula beberapa contoh campur kode dalam bentuk klausa, antara lain:

Situs itu dibangun ulang sama nabi ibrahim dan berdoa "rabbana inni askantum mindhurriyati biiwadin ghairihi zarin 'inda baitikal muharrom, rabbana liyuqimusholata wajdatamminannasi dhawii ilaihim warzuqhum

la'alahum

(CK/AM/2018)

wah itu tugu i love you ku sama nenekmu hawa (CK/AM/2018)

maka kemudian semua berlombalomba bikin manaroh sampe jakarta bernama menara(CK/AM/2018) islam yang tidak grasa-grusu mampu ngayomi seluruh manusia yang berbeda beda seperti Rasulullah yang anittum hariisun alaikum bil mukminiina rouufurrohim (CK/AM/2018)

Dari kutipan tersebut
menjelaskan adanya campur
kode berupa klausa, dengan
percampuran antara bahasa
Indonesia, bahasa Inggris dan
bahasa Arab.

\section{SIMPULAN}

Berdasarkan hasil penelitian tentang interaksi bahasa ceramah Gus Muwafiq dalam acara maulid Nabi di istana Bogor dapat disimpulkan sebagai berikut:

1. Variasi bahasa yang digunakan pada ceramah Gus Muwafiq dalam acara maulid Nabi di istana Bogor terbagi menjadi empat ragam, yaitu ragam resmi, usaha, santai dan akrab. Dari keempat tersebut ragam santai dan akrablah yang digunakan paling banyak. Ragam tersebut sangat cocok digunakan saat ceramah 
dikarenakan penceramah akan berusaha untuk mengakrabkan dengan pendengar atau audiens lewat bahasa yang mengandung humor. Sehingga pendengar atau audiens memiliki ketertarikan terhadap ceramah yang didengarkan

2. Campur kode yang terdapat pada ceramah Gus Muwafiq dalam acara maulid Nabi di istana Bogor ditemukan bentuk campur kode pada ceramah Gus Muwafiq yaitu berupa kata, frasa, serta klausa.
Holmes, Janet. (2017). An Introduction to Sociolinguistics ( $5^{\text {th }}$ edition). New York: Longman.

Kridalaksana, Harimurti. (2008). Kamus Linguistik. Jakarta : Gramedia Pustaka Utama.

Rahadi, Kunjana. (2010). Kajian Sosiolinguistik. Yogyakarta : Ghalia.

Soeparno. (2009). Dasar-Dasar Linguistik Umum (Edisi 2). Yogyakarta: PT Tiara Wacana.

Sugiyono. (2010). Metode Penelitian Kuantitatif, Kualitatif dan RED. Bandung : Alfabeta.

\section{DAFTAR PUSTAKA}

Arikunto, Suharsimi. (2013). Prosedur Penelitian Suatu Pendekatan Praktik. Jakarta : Rineka Cipta.

Chaer, Abdul \& Leonie Agustina. (2010). Sosiolinguistik Perkenalan Awal. Jakarta: PT Rineka Cipta.

Chaer, Abdul. (2010). Linguistik Umum. Bandung: PT. Rineka Cipta.

Giyoto. (2013). Pengantar Sosiolinguistik. Surakarta : Fataba. 